\title{
Using multi-marker DNA metabarcoding to reveal the diet of a scarce woodland bird
}

\author{
Ewan Stenhouse ${ }^{1}$, Paul Bellamy ${ }^{2}$, Will Kirby ${ }^{2}$, Ian Vaughan ${ }^{1}$, Lorna Drake ${ }^{3}$, Angela \\ Marchbank $^{4}$, Trudy Workman ${ }^{5}$, William Symondson ${ }^{1}$, and Pablo Orozco-terWengel ${ }^{1}$ \\ ${ }^{1}$ Cardiff University \\ ${ }^{2}$ Royal Society for the Protection of Birds \\ ${ }^{3}$ Affiliation not available \\ ${ }^{4}$ Cardiff University College of Biomedical and Life Sciences \\ ${ }^{5}$ Cardiff University Cardiff School of Biosciences
}

October 27, 2021

\begin{abstract}
Understanding the role diet plays in the structure of food webs is vital, and dietary knowledge is key for conservation management success. There is limited knowledge of the diets of woodland bird species, due largely to difficulties in accurately identifying plant and invertebrate taxa being consumed. Here, we show the effectiveness of multi-marker faecal metabarcoding to provide the most in-depth dietary analysis of a generalist passerine, the Hawfinch (Coccothraustes coccothraustes, Linnaeus), to date. Faecal samples were obtained from 2016-2019 from Hawfinch populations prior to and during the breeding season throughout the UK. DNA was extracted from 263 samples and amplified using Internal Transcribed Spacer 2 (ITS2) and cytochrome C oxidase subunit I (COI) barcodes. Using high-throughput sequencing (HTS), we identified 49 and 97 ITS2 and COI zero radius operational taxonomic units (zOTUs) respectively which equated to reputed dietary items. The herbivorous element of Hawfinch diet was dominated by naturally occurring taxa such as beech (Fagus sylvatica, Linnaeus), hornbeam (Carpinus betulus, Linnaeus) and oak (Quercus sp., Linnaeus). The most taxon rich and commonly recorded invertebrate taxon identified was Lepidoptera. We found Hawfinch diet varied spatially, as well as between sexes. Hawfinch showed broad dietary plasticity and utilised multiple resources within their foraging environments. Our study shows the potential of multi-marker DNA metabarcoding to reveal subtle dietary differences, but also highlights the challenges of studying omnivorous species using metabarcoding methods.
\end{abstract}

\section{Using multi-marker DNA metabarcoding to reveal the diet of a scarce woodland bird.}

Ewan H. Stenhouse ${ }^{1,2}$, Paul Bellamy ${ }^{2}$, Will Kirby ${ }^{2}$, Ian P. Vaughan ${ }^{1}$, Lorna E. Drake ${ }^{1}$, Angela Marchbank ${ }^{1}$, Trudy Workman ${ }^{1}$, William O.C. Symondson ${ }^{1}$ and Pablo Orozco-terWengel ${ }^{1}$

${ }^{1}$ School of Biosciences, Cardiff University, Cardiff, Wales, UK

${ }^{2}$ RSPB Centre for Conservation Science, The Lodge, Sandy, UK

\section{Correspondence}

Ewan H. Stenhouse and Pablo Orozco-terWengel, School of Biosciences, Cardiff University, Cardiff, CF10 3AX, Wales, UK.

Email: StenhouseEH@cardiff.ac.uk and orozco-terwengelpa@cardiff.ac.uk

\section{Abstract}


Understanding the role diet plays in the structure of food webs is vital, and dietary knowledge is key for conservation management success. There is limited knowledge of the diets of woodland bird species, due largely to difficulties in accurately identifying plant and invertebrate taxa being consumed. Here, we show the effectiveness of multi-marker faecal metabarcoding to provide the most in-depth dietary analysis of a generalist passerine, the Hawfinch (Coccothraustes coccothraustes, Linnaeus), to date. Faecal samples were obtained from 2016-2019 from Hawfinch populations prior to and during the breeding season throughout the UK. DNA was extracted from 263 samples and amplified using Internal Transcribed Spacer 2 (ITS2) and cytochrome C oxidase subunit I (COI) barcodes. Using high-throughput sequencing (HTS), we identified 49 and 97 ITS2 and COI zero radius operational taxonomic units (zOTUs) respectively which equated to reputed dietary items. The herbivorous element of Hawfinch diet was dominated by naturally occurring taxa such as beech (Fagus sylvatica, Linnaeus), hornbeam (Carpinus betulus, Linnaeus) and oak (Quercus sp., Linnaeus). The most taxon rich and commonly recorded invertebrate taxon identified was Lepidoptera. We found Hawfinch diet varied spatially, as well as between sexes. Hawfinch showed broad dietary plasticity and utilised multiple resources within their foraging environments. Our study shows the potential of multimarker DNA metabarcoding to reveal subtle dietary differences, but also highlights the challenges of studying omnivorous species using metabarcoding methods.

Keywords

bird, Coccothraustes coccothraustes, diet, Hawfinch, metabarcoding, omnivory

\section{Introduction}

To gain a greater understanding of trophic interactions within the environment it is critical to have an indepth understanding of species' diet (Rytkönen et al., 2019). Our understanding of biodiversity and ecosystem functions is significantly increased by investigating spatial and temporal variation in trophic interactions within food webs (Rytkönen et al., 2019; Yu et al., 2012). Estimating diet composition can provide knowledge crucial for understanding the structure of ecological communities and the flow of energy and nutrients (Kartzinel et al., 2015; Nielsen, Clare, Hayden, Brett, \& Kratina, 2017). Furthermore, characterising consumers' resources can provide information about niche specialisation at both inter- and intra-specific scales (Kratina, LeCraw, Ingram, \& Anholt, 2012). The accurate identification of components within an omnivorous diet is however, still considered challenging (da Silva et al., 2019; De Barba et al., 2014; Tercel, Symondson, \& Cuff, 2021). Due to the costly, laborious and taxonomically demanding nature of exploring omnivorous diet, studies attempting to elucidate all dietary aspects are rare (Pompanon et al., 2012; Tercel et al., 2021).

Morphology-based methods of diet analysis can be time consuming and biased towards identification of distinguishable and intact undigested or semi-digested dietary items (Pompanon et al., 2012; Symondson, 2002). Additionally, morphology-based methodologies often record ingested taxa at a coarse taxonomic resolution, missing subtle differences in the taxa consumed and resulting in a lack of ability to make fine scale inferences relating to species' ecology (Mata et al., 2016). The use of molecular techniques such as high-throughput sequencing (HTS) in conjunction with DNA barcoding, referred to as "metabarcoding" is being frequently utilised to assess the diet of a range of organisms (Cuff et al., 2021; Evens et al., 2020; Kartzinel \& Pringle, 2020; Thompson \& Newmaster, 2014; Zalewski, Szymura, Kowalczyk, \& Brzeziński, 2021). This technique requires minimal a prioriknowledge on the dietary composition of the target organism (Alberdi et al., 2017; Valentini et al., 2009) and a wide range of ingested taxa can be identified to fine taxonomic levels (King, Read, Traugott, \& Symondson, 2008). For the application of metabarcoding to study bird diet, faecal samples are highly suitable, as they contain residual dietary DNA and can be collected easily to study species which may otherwise have been difficult to locate or directly observe (Pompanon et al., 2012; Taberlet, Bonin, Zinger, \& Coissac, 2018).

Within metabarcoding studies, detection of plant species have traditionally used sections of plant genes $r b c L$ and matK, which, when used in conjunction, have the power to provide up to $75 \%$ species-level discrimination (de Vere et al., 2012). Limitations on amplicon length in HTS (maximum of $2 \times 300$ base pair reads on an Illumina Miseq), as well as primers designed to amplify short barcodes in order to detect 
DNA in degraded samples (Ando et al., 2013; Dunn et al., 2018; Pompanon et al., 2012) has resulted in these gene regions providing reduced taxonomic resolution in analysis of faecal samples (Pompanon et al., 2012). The Internal Transcribed Spacer 2 (ITS2) nuclear gene has been proposed as a suitable barcode for herbivorous dietary analysis (Moorhouse-Gann et al., 2018). Universal primers targeting the ITS2 region have been developed, producing amplicons between 187-380 base pairs (Dunn et al., 2018; Moorhouse-Gann et al., 2018). This has enabled the most variable region within the gene to be targeted, with the amplicon length suitable for use within DNA metabarcoding studies of the Turtle dove (Streptopelia turtur, Linnaeus), Pink pigeon (Nesoenas mayeri, Prévost) and Telfair's skink (Leiolopisma telfairii, Desjardin) (Dunn et al., 2018; Moorhouse-Gann, 2017; Moorhouse-Gann et al., 2018). In a diet which contains a wide range of invertebrate taxa, DNA barcodes from the COI mitochondrial gene region have become the standard and are used in many species-level identification studies (Kress, García-Robledo, Uriarte, \& Erickson, 2015). This is due to the extensive taxonomic coverage and depth within the Canadian, European, UK and USA taxonomic COI reference sequence databases (Porter \& Hajibabaei, 2018). Such large databases reduce the possibility of false taxonomic assignment and improve higher taxonomic resolution (Andújar, Arribas, Yu, Vogler, \& Emerson, 2018; Porter \& Hajibabaei, 2018; Somervuo et al., 2017).

Despite birds being one of the most studied animal classes, few studies have used molecular techniques to improve understanding of their trophic ecology (Alonso et al., 2014). In comparison with studies on mammals, in particular bats, the application of faecal metabarcoding within passerines studies is limited. However, this is an evolving field, with research being undertaken on an expanding number of passerine species (da Silva, Mata, Lopes, Lopes, \& Beja, 2020; Shutt et al., 2020). For woodland birds that forage high in the canopy and are often hidden from view, obtaining accurate identification of dietary items through observation alone is particularly challenging, and many studies simply use foraging location to infer food availability and individual fitness (Charman, Smith, Dodd, Gruar, \& Dillon, 2012; Mackenzie, Hinsley, \& Harrison, 2014). Within temperate environments, passerine birds often demonstrate a broad dietary range, incorporating a wide range of taxa (Cholewa \& Wesołowski, 2011; Shutt et al., 2020), however, dietary variability within generalist woodland species is relatively poorly understood. It has been proposed that the diet of generalists could vary spatiotemporally, based upon resource availability and preferences of the consumer. This variation within the diet may result in geographical patterns in population density, breeding productivity, and local adaptation to resource use (Shutt et al., 2020).

The Hawfinch (Coccothraustes coccothraustes, Linnaeus) is one of many bird species closely associated with woodland habitats to have shown major declines in the UK over a period of a few decades (Kirby et al., 2018). Hawfinch breed across the Palearctic, with Britain its western range limit (Kirby et al., 2015). While little is known about Hawfinch ecology, studies show Hawfinches have declined across Britain, with the species now too rare to have regular status assessments by national annual monitoring schemes (Kirby et al., 2015). Instead, population change is inferred from distribution data compiled from bird atlas surveys (Balmer et al., 2013). These atlas data indicate a $76 \%$ reduction in the number of $10 \mathrm{~km}$ squares occupied between 1968 and 2011 (Kirby et al., 2015, 2018) and are further evidenced by Langstonet al. (2002), who estimated a $40 \%$ population decline between the mid 1980's to the late 1990's. Hawfinch dietary studies are limited, with all previous information obtained through personal observations. Hawfinch are thought to be dietary specialists due to morphological adaptations (a large, powerful bill) allowing them to feed on large tree seeds such as cherry (Prunus sp., Linnaeus), hornbeam (Carpinus betulus, Linnaeus), beech (Fagus sylvatica, Linnaeus) and Wych elm (Ulmus glabra, Hudson) (Mountford, 1957). During the breeding season (typically from April to June), Hawfinch diet has been observed to include sycamore (Acer pseudoplatanus , Linnaeus), hawthorn (Crataegus monogyna, Jacquin), blackthorn (Prunus spinosa, Linnaeus), wild service tree (Sorbus torminalis , Crantz), dogwood (Cornus alba , L'Héritier), larch (Larix decidua, Miller) and oak (Quercus sp., Linnaeus) (Bijlsma, 1998; Bryant, 2011; Mountford, 1957; Tomiałojć, 2012; von Haartman, 1978). Hawfinch incorporate invertebrates into their diet, particularly during the breeding season to provide sufficient nutrition for egg production, consuming Lepidoptera, Coleoptera, Hemiptera, Annelida, Gastropoda and Araneae (Mountford 1957).

In this study we used multi-marker DNA metabarcoding to construct a high-resolution diet profile of a 
woodland passerine, aiming to elucidate the taxonomic composition and richness, as well as showing that HTS is a powerful approach for analysing species interactions. We hypothesised that Hawfinch diet would show variation across: (a) study sites and (b) sexes. This study also discusses the suitability of multi-marker metabarcoding approaches for exploring omnivory.

\section{Materials and Methods}

\subsection{Study sites and field data collection}

Fieldwork was conducted in the period March to July of 2016-2019 at 11 woodland sites in the UK. Sites selected were pre-existing Hawfinch ringing studies study areas within the Wye Valley, Dolgellau, Cardiff, the New Forest and Norfolk (Figure 1). The artificial feed sites used to attract Hawfinches for capture have been operational for a number of years within regions of Hawfinch population strongholds (Clements, 2013; Kirby et al., 2018). Study $s$ ites were broadly typical of British mixed broadleaved woodland, with sites in the Wye Valley and north Wales dominated by beech, oak and ash (Fraxinus excelsior, Linnaeus). The study site located in Norfolk was a mixed woodland consisting of lime (Tilia sp., Linnaeus), ash and maples (Acer sp., Linnaeus), while the New Forest site was dominated by oak, with an understorey flora comprising of Holly (Ilex sp., Linnaeus) and bramble (Rubus sp., Linnaeus). All site locations are approximate for anonymity.

Hawfinches were caught by trained bird ringers, operating under British Trust for Ornithology (BTO) approved licences using either mist or whoosh nets. For each bird captured morphometric data and time of capture were recorded, including maximum chord wing length, sex and body mass (Svensson, 1992). Hawfinches were individually placed within a clean, paper bag which was then placed inside a cotton bag and left for 10-20 minutes until the bird defecated. To avoid excessive stress, if birds had not defecated within this time frame they were processed and released. Each faecal sample was removed from the paper bags using a new, clean plastic toothpick to minimise contamination. Samples were placed in separate $2 \mathrm{ml}$ Eppendorf tubes, and frozen to $-20^{\circ} \mathrm{C}$ at $1-8 \mathrm{~h}$ after collection.

\subsection{Dietary analysis}

DNA was extracted from a total of 365 faecal samples using the Qiagen QIAamp DNA Stool Mini Kit (Qiagen, UK) with modifications designed to improve DNA yield from avian faeces, following Shutt et al.(2020). Samples were extracted in batches of 23 with an additional negative control containing no DNA. We used primers UniplantF, 5'-TGTGAATTGCARRATYCMG-3' and UniPlantR 5'-CCCGHYTGAYYTGRGGTCDC-3' to amplify a 187-387-bp fragment covering the ITS2 region of plant nuclear DNA (Moorhouse-Gann et al., 2018). For amplification of invertebrate DNA, mlCOIintF, 5'-GGWACWGGWTGAACWGTWTAYCCYCC-3' (Leray et al.2013) and Nancy 5'-ACTAGCAGTACCCGGTAAAATTAAAATATAAACTTC-3', (Simonet al. 1992) were used following selection and modification by Stockdale (2018) for amplification of a 306-bp fragment of the COI region. Primer sets were validated by Stockdale (2018) to ensure DNA amplification of the expected range of taxa. A two-stage PCR process involved initial amplification of the target regions followed by the addition of a unique combination of 10-bp molecular identifier tags (MID-tags), with samples having a unique pairing of forward and reverse tags for subsequent sample identification. Within each PCR 96-well plate, 12 negative (extraction and PCR) and two positive controls were included following Taberlet et al. (2018). Amplicons were multiplexed into five pools, each containing between 63 and 186 samples. Library preparation for Illumina sequencing was undertaken via NEXTflex Rapid DNA-Seq kit (Bioo Scientific, Austin, USA), with a unique adapter added to each pool. Pools were diluted to 4nM and quantified using Qubit dsDNA High-sensitivity Assay Kits. Finally, the diluted pools were combined equimolarly and sequenced on a MiSeq desktop sequencer via a v2 chip with $2 \times 250 \mathrm{bp}$ paired-end reads (expected capacity 24-30,000,000 reads). Due to the unbalanced nature of the amplicon libraries, a 15\% PhiX buffer was added to the sequencing run in order to improve cross-talk and phasing calculations.

\subsection{Identification of dietary taxa}

The Illumina run generated 6,328,388 and 12,307,560 ITS2 and COI reads respectively. All reads were checked for truncation, quality checked, filtered and assigned taxonomic identification following Drake et al., 
(2021). All read counts less than the maximum in unused-MID tag combinations and negative controls for each respective zero radius OTU (zOTU) were removed prior to statistical analysis. Read counts of nonpositive control taxa detected within positive controls were calculated as a percentage of the maximum read count for that taxon. The greatest of these percentages was then applied as a measure of read percentage to be removed from each taxon. This accounts for over-represented taxa tag jumping or "leaking" into other samples during sequencing. Optimal thresholds of $3 \%$ and $1 \%$ were applied to ITS2 and COI data respectively. No known lab contaminants such as German cockroach (Blatella germanica, Linnaeus) or non-target taxa that could be identified as lab contamination were detected in either library. Data from respective ITS2 and COI libraries were aggregated together to form a single taxon list for each marker, and non-target taxa such as fungi and gastrotrichs were removed. In order to standardise the taxonomic level and create evenness for analysis, all taxa were converted to genus-level, as some zOTUs could not be resolved to species.

\subsection{Statistical analysis}

For all statistical analysis, the presence/absence of each taxonomic unit within a sample was used instead of read count, as the latter is not an accurate representation of abundance due to amplification biases (Clare, Symondson, \& Fenton, 2014; Yu et al., 2012). Control samples were excluded from the analyses. All statistical analysis were carried out in R version 3.6.3 (R Core Team, 2020) unless otherwise stated.

To evaluate the most prevalent plant and invertebrate taxa within Hawfinch diet, the number of samples in which a dietary zOTU occurred (frequency of occurrence), was calculated. In order to estimate the total dietary niche breadth, the specpool function in R's vegan package (Oksanen et al., 2019) was used to calculate Chao's incidence-based estimator of richness (Chao \& Jost, 2012; Oksanen et al., 2019). This is based upon presence/absence of dietary taxa found in sample sites, and gives a single estimate for a collection of sampling sites (Oksanen et al., 2019). Observed species richness divided by the Chao estimate gave the proportion of total dietary diversity detected. Species accumulation curves were also produced using the poolaccumfunction within the vegan package, relating the overall dietary diversity captured to the number of faecal samples analysed. To determine whether plant or invertebrate taxonomic richness in Hawfinch diet was greater, a Wilcoxon matched-pairs test was undertaken to test for a significant difference in the median species richness of plant and invertebrate taxa detected. Only Hawfinch samples which provided taxonomic results for both invertebrate and plant taxa were included. Based upon ringing recapture data, no individual Hawfinch that had tested positive for both plant and invertebrate DNA was included more than once.

To test our hypotheses that diet varied among locations and between the sexes we compared dietary composition between sampling regions and sexes using multivariate generalised linear models (MGLMs) using the functionmanyglm within the package mvabund (Wang, Naumann, Eddelbuettel, John, \& Warton, 2012). Regions were broadly categorised into: Wye Valley, Dolgellau, north Cardiff, New Forest and Norfolk, as some regions contained multiple catching sites. Where an individual was sampled more than once, data was used from the first capture only to avoid pseudo replication and subsequent biases. The functionanova.manyglm in mvabund was used to test the significance of each term within the overall model and the p.uni = "adjusted" argument was implemented to perform tests for each species in turn, adjusting the $p$-values with Holm's step down resampling algorithm (Westfall \& Young, 1993). Parametric bootstrap (Monte Carlo) resampling was applied to test for dietary differences, ensuring inferences took into account correlation between variables (Wang et al., 2012). When necessary, pairwise comparisons were performed using thepairwise.comp function of anova.manyglm. Models were simplified using the step function based upon the lowest Akaike's information criterion (AIC) value. For all models, diagnostic plots were checked to ensure model assumptions were met. Dietary differences were visualised using non-metric multidimensional scaling analysis (nMDS) via the function metaMDS in the vegan package (Oksanen et al., 2019). The nMDS was performed with Jaccard dissimilarities in two-dimensional space $(\mathrm{k}=2)$. Spider plots were produced using nMDS results via ordispider and plotted through ggplot2 (Wickham, 2016). Singletons and outliers were removed to visually improve the ordination.

\section{Results}




\subsection{Sampling completeness}

Plant DNA was successfully amplified from 262 faecal samples. We identified 49 plant zOTUs of which $86 \%$ could be identified to species and $100 \%$ to genus (Table S1). The most common taxa detected were beech (38.5\% of samples), sunflower seed (Helianthus sp., Linnaeus), provided ad libitum throughout the year at all feed sites, (30.5\% of samples) and hornbeam (16.0\% of samples). At the genus level, 30 genera were detected in Hawfinch diet. Across the study sites, $78.7 \%$ of the available dietary diversity at genus level was detected, where the total extrapolated estimated genera diversity (Chao estimate) was $38.1 \pm 8.2$ (Figure 3). Invertebrate DNA was extracted successfully from 120 faecal samples. Of the 90 invertebrate zOTUs identified, $92 \%$ were identified to species level and $100 \%$ to genus (Table S2). The most common taxa detected were the winter moth (Operophtera brumata, Linnaeus) (26.7\% of samples), mottled umber (Erannis defoliaria, Clerck) (22.5\% of samples) and tree slug (Lehmannia marginata, O.F.Müller) (22.5\% of samples). At the genus level, 74 genera were detected in Hawfinch diet, with $62.4 \%$ of the available dietary diversity detected across the sampling regions. The extrapolated total estimated genera diversity (Chao estimate) was 118.6 \pm 22.6 (Figure 5). A Wilcoxon matched-pairs test revealed a significant difference between plant and invertebrate taxonomic richness within the diet of Hawfinch $(\mathrm{V}=1436, p=<0.001)$ (Figure 2). The mean number per faecal sample of plant genera detected in Hawfinch diet was 2.3, while the mean number of invertebrate taxa was 3.3.

\subsection{Dietary differences}

Herbivorous dietary composition differed between sampling regions $\left(\mathrm{R}^{2}=0.05\right.$, MGLM: LRT $=266.8, p=$ $<0.001$ ). Univariate analysis revealed six genera were associated with regional differences: Betula sp. (LRT $=21.3, p=0.002)$,Carpinus sp. (LRT $=36, p=0.001)$, Fagus sp. (LRT $=56.4, p=0.001)$, Helianthus sp. $(\mathrm{LRT}=51.6, p=0.001)$, Quercus sp. (LRT $=19.2, p=0.002)$ and Ulmus sp. (LRT $=30.5, p=0.001)$ (Table S3). Specifically, Fagus sp. and Ulmus sp. were detected with the highest frequency in the Wye Valley (62.1\% and $16.4 \%$ respectively), with birds sampled from north Wales showing the highest frequency for Helianthus sp. (50.9\%). Quercus sp. were detected at the highest frequency in Hawfinches sampled within the New Forest (57.9\%). The nMDS visualises the patterns of genus level consumption revealed from the manyglm model (Figure 4). All sampling regions show some degree of dietary overlap, while the diets of Hawfinches sampled from the regions of north Cardiff and the Wye Valley appear the most similar to each other. Pairwise comparisons revealed significant genus level dietary composition differences between all site comparisons except the Wye Valley and north Cardiff $(p=0.323)$ (Table S4). Invertebrate dietary composition differed between sexes $\left(\mathrm{R}^{2}=0.07\right.$, LRT $\left.=109.7, p=0.003\right)$, however no specific invertebrate genera were associated with the dietary differences detected. The nMDS visualises the patterns of genus level consumption revealed from the manyglm model (Figure 6).

\section{Discussion}

This study demonstrates that faecal metabarcoding can provide detailed insights into the omnivorous diet of a scarce woodland bird. Previously unrecorded dietary items were found, despite sampling completeness recorded at $78.7 \%$ and $62.4 \%$ for plant and invertebrate genera, respectively. This highlights the power of DNA metabarcoding to reveal fine-scale taxonomic detail within dietary research. Our results suggest that during the breeding season Hawfinch have a wide dietary niche breadth for both plant and invertebrate species, supporting the hypotheses that Hawfinch diet differs between populations geographically and between sexes. As found in other recent studies of bird diet (da Silva et al., 2020; Jedlicka, Vo, \& Almeida, 2017; Mitchell, Horsburgh, Dawson, Maher, \& Arnold, 2021; Shutt et al., 2020; Sullins et al., 2018), the use of molecular techniques has revealed an unsuspected wide range of dietary items and provides the first comprehensive analysis of omnivory within Hawfinch diet. Although this study documents over 100 taxa consumed, previously recorded common food resources such as beech, cherry and Lepidoptera (Mountford, 1957; Newton, 1967) clearly still play a dominant role in diet.

Diet is likely to reflect a mixture of prey availability, abundance and preference, with Hawfinch consumed a broader range of invertebrate taxa in comparison to plant taxa, reflecting what may be naturally available 
within the environment. Food preference, rather than availability or abundance has been found to contribute towards dietary shifting from invertebrates to fruit, potentially enabling birds to seasonally balance nutrient and energy intake (Marshall, Dick, \& Guglielmo, 2016). Invertebrates are typically a high protein to calorie ratio food resource, with certain species providing specific nutritional value, for example spiders provide high levels of the amino acid cysteine (Marshall et al., 2016; Ramsay \& Houston, 2003). Hawfinch egg laying begins around mid April (Kirby, Stanbury, Bellamy, \& Lewis, 2019), and the presence of invertebrates within the diet during the breeding season has been recorded in other passerine dietary studies conducted over similar temporal periods (Newton, 1967; Shutt et al., 2020). This may help to provide specific nutrients beneficial to breeding physiology, such as egg production in females, as well as providing high protein food for chicks (Marshall et al., 2016). These dietary patterns are commonly observed in other passerine species such as chaffinch (Fringilla coelebs, Linnaeus) (Holland, Hutchison, Smith, \& Aebischer, 2006).

Many taxa present in the diet were rare, as has been documented in previous faecal metabarcoding studies on generalist passerines (Shutt et al., 2020; Sottas et al., 2020). However, our findings on the more frequent components of Hawfinch diet agree closely with previous observations of this species (Bijlsma, 1998; Mountford, 1957). Previous studies found seeds of hornbeam, cherry and maple were important throughout the year (Bijlsma, 1998; Mountford, 1957), with buds of ash, maple and beech as well as Lepidoptera becoming important food resources during spring and summer (Bijlsma, 1998). The importance of beech as a food resource was confirmed in this study, being the most prevalent plant taxon (detected in $38.5 \%$ of samples). It is well understood that birds must balance food handling times with net energy intake, and a resource is deemed more profitable if it has a higher energy reward per unit handling time (Molokwu, Nilsson, \& Olsson, 2011). It is known that Hawfinch commonly feed on beech nuts during autumn and winter months (Mountford, 1957) due to the moderately high fat and carbohydrate levels of the beechnuts compensating for energy losses due to cold weather during winter (Renner et al., 2013). The onset of the breeding season can drive changes in feeding preferences as nutritional needs become higher (Lima, 2009). As the sampling in this study began during the pre-breeding season and continued to the end of summer, Hawfinch may have been gaining a high energy reward from feeding on any remaining available beech nuts, but also obtaining similar nutritional benefits from the increased availability of beech buds in the spring. Beech buds have been shown to contain $>15 \%$ fat (Lebl, Kürbisch, Bieber, \& Ruf, 2010), and this may be an important energetic requirement for Hawfinch to boost condition before and during the breeding season.

Lepidoptera, Coleoptera, Hemiptera, Annelida, Gastropoda and Araneae have all been observed as prey at the order level (Mountford, 1957) and all (excluding Annelida) were detected within this study. The high prevalence of winter moth within Hawfinch diet is not unexpected, as this larva is an important food resource for other woodland passerine species, such as nestling tits (Perrins, 1991). The earliest date winter moth was detected within the diet was mid-April, with prevalence increasing throughout April and May. Kirby et al. (2019) found Hawfinch egg laying commonly started during the third week of April and peaked in mid May. This temporal increase in the number of nests coincides with the increased incidence of winter moth within the diet, and most likely corresponds to a change in the availability of winter moth larvae. This finding raises the possibility that Hawfinch may be using availability of winter moth as a breeding cue, as has been suggested in other passerine species (Shutt et al., 2020). In contrast, the high prevalence of tree slug within the diet was unexpected, as it was previously thought only snails were consumed (Mountford, 1957). This may be explained by the availability of algae and lichens within woodland, which are the main components of tree slug diet (Kappes, 2006). During wet weather, tree slugs feed on algae growing on tree trunks, but remain under the bark of dead timber during unsuitable weather (Kappes, 2006). Thus, tree slugs may be taken during periods of high rainfall when foraging efficiency for defoliating Lepidoptera is reduced (Morganti, Rubolini, Caprioli, Saino, \& Ambrosini, 2017; Ortega-Jimenez \& Dudley, 2012).

The metabarcoding results revealed oak to be widely prevalent within the diet, something not reported in Mountford's species monograph (1957). Past research undertaken on Hawfinch diet during winter (months unspecified) and during the breeding season (April to August), broadly fitted with the sampling period of this study, and it is surprising therefore, that oak was not observed as a food resource. Hawfinch dietary studies have focused on direct observations of feeding, and while this method was widely used at the time of 
Mountford (1957), direct observation has known limitations, such as observer bias and error, as well as results being influenced by data recorded from habitats in which a species is most observable (Matthews, Ridley, Kaplin, \& Grueter, 2020). Furthermore, whether oak species have specific dietary importance is dependent, in part, on the plant tissue type consumed and the nutritional value. While this was not investigated within this study, it is encouraged for further research. Having this nutritional information may inform how Hawfinch food preferences change throughout the breeding season and whether there is specific temporal value available across taxa.

Plant taxa detected within Hawfinch diet varied between geographical regions. This spatial variation is consistent with similar metabarcoding studies of birds and insectivorous bats (Clare, Symondson, Broders, et al., 2014; McClenaghan, Nol, \& Kerr, 2019; Shutt et al., 2020). This could indicate local dietary specialisation, however it is more probable that Hawfinch are flexible in dietary choice and these patterns arise from changing availability of food resources. This may be a result of variation in tree species abundances within each study region. This variation in resource use can be seen in the nMDS plot (Figure 3). While there is a degree of overlap between all regions, the Wye Valley and north Cardiff sampling regions are situated closer together, indicating dietary taxa detected from Hawfinch sampled within these regions show higher levels of similarity than dietary taxa from Hawfinch sampled in north Wales.

The sexual differences in invertebrate dietary composition is likely due to behavioural, rather than morphometrical differences between males and females. Hawfinch are judged to have minimal sexual dimorphism, however biometric measurements such as bill length/depth were not recorded for this study and therefore future work should incorporate this in order to improve understanding of possible intra-specific variation. This is one of only two studies which have used DNA metabarcoding to detect monomorphic passerine species exhibiting sexual dietary differences (see da Silva et al., 2020). It has been suggested in some bird species that females have reduced foraging ranges in order to be closer to offspring, and as a result, may feed on more abundant or predictable items, even if these items are less nutritious (da Silva et al., 2020; Sunde, Bølstad, \& Møller, 2003). Freeman (2014) found vertical segregation between the sexes of two New Guinean whistlers (Pachycephala sp., Schlegel), with little sexual dimorphism, attributed to territory defence and intersexual food resource differentiation.

It is also important to acknowledge the possibility of secondary consumption via lepidopteran taxa within the diet (Tercel et al., 2021), which may result in indirect species associations. Secondary consumption may result in falsely inflated detection of plant taxa through co-amplification of plant DNA within the guts of lepidopteran taxa consumed by Hawfinch. Ecologically, it is known that Hawfinch feed primarily within the canopy (Mountford, 1957), and will only come to the ground to feed on fallen seed in late winter. This suggests that most invertebrate taxa were obtained from the vegetation or bark within the tree canopy, resulting in possible accidental ingestion of plant taxa when gleaning prey items from trees. Due to metabarcoding methods being unable to determine which plant tissue is being consumed, in conjunction with Hawfinch also feeding on the same plant taxa as their prey at similar times of the year, differentiating what is "true" secondary predation is extremely challenging.

In conclusion, this study has provided the first molecular insight into the generalist diet of Hawfinch, at a finer resolution than previous work. We demonstrate that the diet of Hawfinch, as predicted, varies both spatially and between sexes. This dietary variation suggests Hawfinch can respond to changing resource availability by showing dietary plasticity. In order to maximise the power of dietary analysis, increasing the temporal scale of sampling would be beneficial for future work, as would measuring invertebrate abundance to compare with diet samples. The diet of nestling Hawfinch could be described and geographic variability of diet assessed in order to quantify the apparent significance of Lepidoptera for Hawfinch and other woodland birds. Furthermore, future research could involve faecal metabarcoding of multiple species from Hawfinch study sites. A large number of co-existing predator species utilise Lepidoptera and other invertebrates during the breeding season including great tit (Parus major, Linnaeus) (Ramakers, Gienapp, \& Visser, 2019), marsh tit (Poecile palustris, Linnaeus) (Wesołowski \& Neubauer, 2017), blue tit (Cyanistes caeruleus, Linnaeus) (Shutt, Burgess, \& Phillimore, 2019) and both great spotted (Dendrocopos major, Linnaeus) and lesser 
spotted (Dendrocopos minor, Linnaeus) (Charman et al., 2012; Smith \& Smith, 2013) woodpecker species. Faecal metabarcoding of adults and nestlings from a range of representative woodland bird species would help quantify the most important prey species, which could in turn inform conservation management to maximise their abundance.

The results of this study were only possible due to the high taxonomic resolution available through metabarcoding methods. As metabarcoding is becoming more prevalent within ecological research, it becomes increasingly important to understand how taxonomic resolution can impact ecological studies, although species-level identification may not always be necessary, depending on hypotheses studied (Brown et al., 2014; Renaud, Baudry, \& Bessa-Gomes, 2020). The study presented is an example of how the utilisation of DNA metabarcoding can increase ecological understanding and improve insights into fine scale ecological patterns.

As this study was focused primarily on elucidating the diet of Hawfinch, priority was given to maximise the number of faecal samples within the HTS methodology. This however, limited the number of technical replicates such as subsampling individual faecal samples throughout the extraction, amplification and sequencing process (Alberdi, Aizpurua, Gilbert, \& Bohmann, 2018). This resulted in the inability to evaluate and amend the stochasticity of the results (Alberdi et al., 2018; Zinger et al., 2019). Artificial communities of known concentrations, or "mock communities" (Forin-Wiart et al., 2018) were also not included for the aforementioned reasons. This resulted in the inability to analyse the sensitivity of the sequencing pipeline among dietary taxa. Compiling a barcode library specific to the study would also be advantageous. While work by (Jones et al., 2021) has resulted in increasing the number of ITS2 sequences within the DNA barcode database by 1105 species, the utilisation of a custom reference database may allow all future research to be conducted at the species level.

\section{Acknowledgements}

EHS was supported by a NERC GW4+ Doctoral Training Partnership studentship from the Natural Environment Research Council (grant NE/L002434/1) and is thankful for the support and additional funding from CASE partner the Royal Society for the Protection of Birds (grant 210-x-1656). The authors thank the Welsh Ornithological Society for providing additional funding. The authors would like to thank Will Kirby and all the members of the Hawfinch ringing group for assistance with sample collection, and to Angela Marchbank and Trudy Workman of the Cardiff University Genomics Hub for assistance with high-throughput sequencing. Thanks also to Lorna Drake and Sarah Davies for training and advice in bioinformatics.

\section{References}

Alberdi, A., Aizpurua, O., Bohmann, K., Gopalakrishnan, S., Lynggaard, C., Nielsen, M., ... Bik, H. M. (2017). Promises and pitfalls of using high-throughput sequencing for diet analysis. Molecular Ecology Resources , 98 (1), 1423-1428. https://doi.org/10.1111/mec.13549

Alberdi, A., Aizpurua, O., Gilbert, M. T. P., \& Bohmann, K. (2018). Scrutinizing key steps for reliable metabarcoding of environmental samples. Methods in Ecology and Evolution , 9 (1), 134-147. https://doi.org/10.1111/2041-210X.12849

Alonso, H., Granadeiro, J. P., Waap, S., Xavier, J., Symondson, W. O. C., Ramos, J. A., \& Catry, P. (2014). An holistic ecological analysis of the diet of Cory's shearwaters using prey morphological characters and DNA barcoding. Molecular Ecology , 23 (15), 3719-3733. https://doi.org/10.1111/mec.12785

Ando, H., Setsuko, S., Horikoshi, K., Suzuki, H., Umehara, S., Inoue-Murayama, M., \& Isagi, Y. (2013). Diet analysis by next-generation sequencing indicates the frequent consumption of introduced plants by the critically endangered red-headed wood pigeon (Columba janthina nitens) in oceanic island habitats.Ecology and Evolution , 3 (12), 4057-4069. https://doi.org/10.1002/ece3.773

Andújar, C., Arribas, P., Yu, D. W., Vogler, A. P., \& Emerson, B. C. (2018). Why the COI barcode should be the community DNA metabarcode for the metazoa. Molecular Ecology , 27 (20), 3968-3975. 
https://doi.org/10.1111/mec.14844

Balmer, D. E., Gillings, S., Caffrey, B. J., Swann, R. L., Downie, I. S., \& Fuller, R. J. (2013). Bird Atlas 2007-11: The breeding and wintering birds of Britain and Ireland. Thetford: BTO Books.

Bijlsma, R. G. (1998). Breeding biology and population trend of Hawfinches Coccothraustes coccothraustes in Flevoland.Limosa, 71 (4), 137-148.

Brown, D. S., Burger, R., Cole, N., Vencatasamy, D., Clare, E. L., Montazam, A., \& Symondson, W. O. C. (2014). Dietary competition between the alien Asian Musk Shrew (Suncus murinus ) and a reintroduced population of Telfair's Skink (Leiolopisma telfairii ).Molecular Ecology , 23 (15), 3695-3705. https://doi.org/10.1111/mec.12445

Bryant, D. (2011). Multi-species groups of finches feeding on Wych Elm fruits in spring. Scottish Birds , 31 , 311-314.

Chao, A., \& Jost, L. (2012). Coverage-based rarefaction and extrapolation: standardizing samples by completeness rather than size.Ecology , 93 (12), 2533-2547. https://doi.org/https://doi.org/10.1890/11-1952.1

Charman, E. C., Smith, K., Dodd, S., Gruar, D. J., \& Dillon, I. A. (2012). Pre-breeding foraging and nest site habitat selection by Lesser Spotted Woodpeckers Dendrocopos minor in mature woodland blocks in England. Ornis Fennica , 89 (3), 182-196.

Cholewa, M., \& Wesołowski, T. (2011). Nestling Food of European Hole-Nesting Passerines: Do We Know Enough to Test the Adaptive Hypotheses on Breeding Seasons? Acta Ornithologica , 46 (2), 105-116. https://doi.org/10.3161/000164511X625874

Clare, E. L., Symondson, W. O. C., Broders, H., Fabianek, F., Fraser, E. E., Mackenzie, A., .. Reimer, J. P. (2014). The diet of Myotis lucifugus across Canada: Assessing foraging quality and diet variability. Molecular Ecology , 23 (15), 3618-3632. https://doi.org/10.1111/mec.12542

Clare, E. L., Symondson, W. O. C., \& Fenton, M. B. (2014). An inordinate fondness for beetles? Variation in seasonal dietary preferences of night-roosting big brown bats (Eptesicus fuscus ). Molecular Ecology , 23 (15), 3633-3647. https://doi.org/10.1111/mec.12519

Clements, R. (2013). A UK population estimate for the Hawfinch.British Birds , 106 , 43-44.

Cuff, J. P., Drake, L. E., Tercel, M. P. T. G., Stockdale, J. E., Orozco-terWengel, P., Bell, J. R., ... Symondson, W. O. C. (2021). Money spider dietary choice in pre- and post-harvest cereal crops using metabarcoding. Ecological Entomology , 46 (2), 249-261. https://doi.org/https://doi.org/10.1111/een.12957

da Silva, L. P., Mata, V. A., Lopes, P. B., Lopes, R. J., \& Beja, P. (2020). High-resolution multi-marker DNA metabarcoding reveals sexual dietary differentiation in a bird with minor dimorphism. Ecology and Evolution , 10 (19), 10364-10373. https://doi.org/10.1002/ece3.6687

da Silva, L. P., Mata, V. A., Lopes, P. B., Pereira, P., Jarman, S. N., Lopes, R. J., \& Beja, P. (2019). Advancing the integration of multi-marker metabarcoding data in dietary analysis of trophic generalists. Molecular Ecology Resources , 19 (6), 1420-1432. https://doi.org/https://doi.org/10.1111/1755-0998.13060

De Barba, M., Miquel, C., Boyer, F., Mercier, C., Rioux, D., Coissac, E., \& Taberlet, P. (2014). DNA metabarcoding multiplexing and validation of data accuracy for diet assessment: Application to omnivorous diet. Molecular Ecology Resources , 14 (2), 306-323. https://doi.org/10.1111/1755-0998.12188

de Vere, N., Rich, T. C. G., Ford, C. R., Trinder, S. A., Long, C., Moore, C. W., .. Wilkinson, M. J. (2012). DNA barcoding the native flowering plants and conifers of wales. PLoS ONE , 7 (6), 1-12. https://doi.org/10.1371/journal.pone.0037945

Drake, L., Cuff, J., Young, R., Marchbank, A., Chadwick, E., \& Symondson, W. (2021). Post-bioinformatic methods to identify and reduce the prevalence of artefacts in metabarcoding data. Authorea Preprints. 
https://doi.org/10.22541/au.161830201.18684167/v1

Dunn, J. C., Stockdale, J. E., Moorhouse-Gann, R. J., McCubbin, A., Hipperson, H., Morris, A. J., ... Symondson, W. O. C. (2018). The decline of the Turtle Dove: Dietary associations with body condition and competition with other columbids analysed using high-throughput sequencing. Molecular Ecology , 27 (16), 3386-3407. https://doi.org/10.1111/mec.14766

Evens, R., Conway, G., Franklin, K., Henderson, I., Stockdale, J., Beenaerts, N., ... Artois, T. (2020). DNA diet profiles with high-resolution animal tracking data reveal levels of prey selection relative to habitat choice in a crepuscular insectivorous bird.Ecology and Evolution , 10 (23), 13044-13056. https://doi.org/10.1002/ece3.6893

Forin-Wiart, M.-A., Poulle, M.-L., Piry, S., Cosson, J.-F., Larose, C., \& Galan, M. (2018). Evaluating metabarcoding to analyse diet composition of species foraging in anthropogenic landscapes using Ion Torrent and Illumina sequencing. Scientific Reports , 8,17091. https://doi.org/10.1038/s41598-018-34430-7

Freeman, B. (2014). Sexual niche partitioning in two species of New Guinean Pachycephala whistlers. Journal of Field Ornithology , 85 (1), 23-30. https://doi.org/10.1111/jofo.12046

Holland, J. M., Hutchison, M. A. S., Smith, B., \& Aebischer, N. J. (2006). A review of invertebrates and seed-bearing plants as food for farmland birds in Europe. Annals of Applied Biology ,150 (3), 403-403. https://doi.org/https://doi.org/10.1111/j.1744-7348.2006.00039.x

Jedlicka, J. A., Vo, A.-T. E., \& Almeida, R. P. P. (2017). Molecular scatology and high-throughput sequencing reveal predominately herbivorous insects in the diets of adult and nestling Western Bluebirds (Sialia mexicana ) in California vineyards. The Auk ,134 (1), 116-127. https://doi.org/10.1642/AUK-16-103.1

Jones, L., Twyford, A. D., Ford, C. R., Rich, T. C. G., Davies, H., Forrest, L. L., . . de Vere, N. (2021). Barcode UK: A complete DNA barcoding resource for the flowering plants and conifers of the United Kingdom. Molecular Ecology Resources , 21 (6), 2050-2062. https://doi.org/https://doi.org/10.1111/1755-0998.13388

Kappes, H. (2006). Relations between forest management and slug assemblages (Gastropoda) of deciduous regrowth forests. Forest Ecology and Management , 237 (1), 450-457. https://doi.org/https://doi.org/10.1016/j.foreco.2006.09.067

Kartzinel, T. R., Chen, P. A., Coverdale, T. C., Erickson, D. L., Kress, W. J., Kuzmina, M. L., ... Pringle, R. M. (2015). DNA metabarcoding illuminates dietary niche partitioning by African large herbivores.Proceedings of the National Academy of Sciences , 112 (26), 8019-8024. https://doi.org/10.1073/pnas.1503283112

Kartzinel, T. R., \& Pringle, R. M. (2020). Multiple dimensions of dietary diversity in large mammalian herbivores. Journal of Animal Ecology , 89 (6), 1482-1496. https://doi.org/https://doi.org/10.1111/13652656.13206

King, R. A., Read, D. S., Traugott, M., \& Symondson, W. O. C. (2008). Molecular analysis of predation: A review of best practice for DNA-based approaches. Molecular Ecology , 17 (4), 947-963. https://doi.org/10.1111/j.1365-294X.2007.03613.x

Kirby, W. B., Bellamy, P. E., Stanbury, A. J., Bladon, A. J., Grice, P. V., \& Gillings, S. (2015). Breeding season habitat associations and population declines of British Hawfinches Coccothraustes coccothraustes . Bird Study , 62 (3), 348-357. https://doi.org/10.1080/00063657.2015.1046368

Kirby, W. B., Stanbury, A. J., Lewis, J., Smith, D. L., Cross, A. V., Grice, P. V., \& Bellamy, P. E. (2018). Nest survival, causes of failure and productivity of British Hawfinches Coccothraustes coccothraustes . Bird Study , 65 (3), 279-289. https://doi.org/10.1080/00063657.2018.1506424

Kirby, W., Stanbury, A., Bellamy, P., \& Lewis, J. (2019). Double-brooding and renesting in British Hawfinches. British Birds , 112, 170-171. 
Kratina, P., LeCraw, R. R. M., Ingram, T., \& Anholt, B. R. (2012). Stability and persistence of food webs with omnivory: Is there a general pattern? Ecosphere , 3 (6), 1-18. https://doi.org/10.1890/ES12-00121.1

Kress, W. J., García-Robledo, C., Uriarte, M., \& Erickson, D. L. (2015). DNA barcodes for ecology, evolution, and conservation. Trends in Ecology and Evolution, 30 (1), 25-35. https://doi.org/10.1016/j.tree.2014.10.008

Langston, R., Gregory, R., \& Adams, R. (2002). The status of the Hawfinch in the UK 1975-1999. British Birds , 95 (4), 166-173.

Lebl, K., Kürbisch, K., Bieber, C., \& Ruf, T. (2010). Energy or information? The role of seed availability for reproductive decisions in edible dormice. Journal of Comparative Physiology B ,180 (3), 447-456. https://doi.org/10.1007/s00360-009-0425-6

Lima, S. L. (2009). Predators and the breeding bird: behavioral and reproductive flexibility under the risk of predation. Biological Reviews , 84 (3), 485-513. https://doi.org/https://doi.org/10.1111/j.1469185X.2009.00085.x

Mackenzie, J. A., Hinsley, S. A., \& Harrison, N. M. (2014). Parid foraging choices in urban habitat and their consequences for fitness.Ibis , 156 (3), 591-605. https://doi.org/https://doi.org/10.1111/ibi.12166

Marshall, T. J., Dick, M. F., \& Guglielmo, C. G. (2016). Seasonal dietary shifting in yellow-rumped warblers is unrelated to macronutrient targets. Comparative Biochemistry and Physiology Part A: Molecular $\mathcal{E}^{3}$ Integrative Physiology , 192 , 57-63. https://doi.org/https://doi.org/10.1016/j.cbpa.2015.11.014

Mata, V. A., Amorim, F., Corley, M. F. V, McCracken, G. F., Rebelo, H., \& Beja, P. (2016). Female dietary bias towards large migratory moths in the European free-tailed bat (Tadarida teniotis ). Biology Letters , 12 (3). https://doi.org/10.1098/rsbl.2015.0988

Matthews, J. K., Ridley, A., Kaplin, B. A., \& Grueter, C. C. (2020). A comparison of fecal sampling and direct feeding observations for quantifying the diet of a frugivorous primate. Current Zoology ,66 (4), 333343. https://doi.org/10.1093/cz/zoz058

McClenaghan, B., Nol, E., \& Kerr, K. C. R. (2019). DNA metabarcoding reveals the broad and flexible diet of a declining aerial insectivore.Auk , 136 (1), 1-11. https://doi.org/10.1093/auk/uky003

Mitchell, L. J., Horsburgh, G. J., Dawson, D. A., Maher, K. H., \& Arnold, K. E. (2021). Metabarcoding reveals selective dietary responses to environmental availability in the diet of a nocturnal, aerial insectivore, the European Nightjar (Caprimulgus europaeus ).Ibis . https://doi.org/https://doi.org/10.1111/ibi.13010

Molokwu, M. N., Nilsson, J.-A., \& Olsson, O. (2011). Diet selection in birds: trade-off between energetic content and digestibility of seeds.Behavioral Ecology , 22 (3), 639-647. https://doi.org/10.1093/beheco/arr025

Moorhouse-Gann, R. (2017). Ecological replacement as a restoration tool: Disentangling the impacts and interactions of Aldabra giant tortoises (Aldabrachelys gigantea) using DNA metabarcoding[Unpublished doctoral dissertation]. Cardiff University.

Moorhouse-Gann, R. J., Dunn, J. C., de Vere, N., Goder, M., Cole, N., Hipperson, H., \& Symondson, W. O. C. (2018). New universal ITS2 primers for high-resolution herbivory analyses using DNA metabarcoding in both tropical and temperate zones. Scientific Reports , 8 . https://doi.org/10.1038/s41598-018-26648-2

Morganti, M., Rubolini, D., Caprioli, M., Saino, N., \& Ambrosini, R. (2017). Rainfall, but not temperature, negatively affects the growth of Blue Tit Cyanistes caeruleus nestlings. Bird Study ,64 (2), 159-167. https://doi.org/10.1080/00063657.2017.1309006

Mountford, G. (1957). The Hawfinch . Collins, London.

Newton, I. (1967). THE ADAPTIVE RADIATION AND FEEDING ECOLOGY OF SOME BRITISH FINCHES. Ibis , 109 (1), 33-96. https://doi.org/10.1111/j.1474-919X.1967.tb00005.x 
Nielsen, J. M., Clare, E. L., Hayden, B., Brett, M. T., \& Kratina, P. (2017). Diet tracing in ecology: Method comparison and selection.Methods in Ecology and Evolution , 9 (2), 278-291. https://doi.org/https://doi.org/10.1111/2041-210X.12869

Oksanen, J., Blanchet, F. G., Friendly, M., Kindt, R., Legendre, P., McGlinn, D., .. Wagner, H. (2019). vegan: Community Ecology Package. R package version 2.5-6. Retrieved from https://cran.rproject.org $/$ package $=$ vegan

Ortega-Jimenez, V. M., \& Dudley, R. (2012). Flying in the rain: hovering performance of Anna's hummingbirds under varied precipitation.Proceedings of the Royal Society B: Biological Sciences ,279 (1744), 3996-4002. https://doi.org/10.1098/rspb.2012.1285

Perrins, C. (1991). Tits and their caterpillar food supply. Ibis ,133 (s1), 49-54. https://doi.org/10.1111/j.1474-919X.1991.tb07668.x

Pompanon, F., Deagle, B. E., Symondson, W. O. C., Brown, D. S., Jarman, S. N., \& Taberlet, P. (2012). Who is eating what: Diet assessment using next generation sequencing. Molecular Ecology , 21 (8), 1931-1950. https://doi.org/10.1111/j.1365-294X.2011.05403.x

Porter, T. M., \& Hajibabaei, M. (2018). Over 2.5 million COI sequences in GenBank and growing. PLOS ONE , 13 (9). Retrieved from https://doi.org/10.1371/journal.pone.0200177

QGIS development team. (2021). QGIS Geographic Information System. QGIS Geographic Information System.

R Core Team. (2020). R: A language and environment for statistical computing, R Foundation for Statistical Computing. Vienna, Austria. Retrieved from https://www.r-project.org

Ramakers, J. J. C., Gienapp, P., \& Visser, M. E. (2019). Phenological mismatch drives selection on elevation, but not on slope, of breeding time plasticity in a wild songbird. Evolution , 73 (2), 175-187. https://doi.org/https://doi.org/10.1111/evo.13660

Ramsay, S. L., \& Houston, D. C. (2003). Amino acid composition of some woodland arthropods and its implications for breeding tits and other passerines. Ibis , 145 (2), 227-232. https://doi.org/https://doi.org/10.1046/j.1474-919X.2003.00133.x

Renaud, E., Baudry, E., \& Bessa-Gomes, C. (2020). Influence of taxonomic resolution on mutualistic network properties. Ecology and Evolution , 10 (7), 3248-3259. https://doi.org/10.1002/ece3.6060

Renner, S. C., Baur, S., Possler, A., Winkler, J., Kalko, E. K. V, Bates, P. J. J., \& Mello, M. A. R. (2013). Food Preferences of Winter Bird Communities in Different Forest Types. PLOS ONE ,7 (12), e53121. Retrieved from https://doi.org/10.1371/journal.pone.0053121

Rytkönen, S., Vesterinen, E. J., Westerduin, C., Leviäkangas, T., Vatka, E., Mutanen, M., .. Orell, M. (2019). From feces to data: A metabarcoding method for analyzing consumed and available prey in a birdinsect food web. Ecology and Evolution , 9 (1), 631-639. https://doi.org/10.1002/ece3.4787

Shutt, J., Burgess, M., \& Phillimore, A. (2019). A Spatial Perspective on the Phenological Distribution of the Spring Woodland Caterpillar Peak. The American Naturalist, 194 . https://doi.org/10.1086/705241

Shutt, J. D., Nicholls, J. A., Trivedi, U. H., Burgess, M. D., Stone, G. N., Hadfield, J. D., \& Phillimore, A. B. (2020). Gradients in richness and turnover of a forest passerine's diet prior to breeding: A mixed model approach applied to faecal metabarcoding data. Molecular Ecology , 29 (6), 1199-1213. https://doi.org/10.1111/mec.15394

Simon, L., Lalonde, M., \& Bruns, T. D. (1992). Specific amplification of 18S fungal ribosomal genes from vesicular-arbuscular endomycorrhizal fungi colonizing roots. Applied and Environmental Microbiology ,58 (1), 291-295. Retrieved from http://aem.asm.org/content/58/1/291.abstract 
Smith, K. W., \& Smith, L. (2013). The effect of supplementary feeding in early spring on the breeding performance of the Great Spotted Woodpecker Dendrocopos major . Bird Study , 60 (2), 169-175. https://doi.org/10.1080/00063657.2013.776004

Somervuo, P., Yu, D., Xu, C., Ji, Y., Hultman, J., Wirta, H., \& Ovaskainen, O. (2017). Quantifying uncertainty of taxonomic placement in DNA barcoding and metabarcoding. Methods in Ecology and Evolution, 8 (4), 398-407. https://doi.org/10.1111/2041-210X.12721

Sottas, C., Reif, J., Kreisinger, J., Schmiedová, L., Sam, K., Osiejuk, T. S., \& Reifová, R. (2020). Tracing the early steps of competition-driven eco-morphological divergence in two sister species of passerines. Evolutionary Ecology , 34 (4), 501-524. https://doi.org/10.1007/s10682-020-10050-4

Stenhouse, E.H., Bellamy, P., Kirby, W., Vaughan, I.P., Drake, L.E, Marchbank, A., Workman, T., Symondson, W.O.C., \& Orozco-terWengel, I.P. (2021). MOTU presence absence data . Retrieved from

Stockdale, J. E. (2018). Using high-throughput sequencing to track habitat use by thrushes exploiting heterogeneous farmland landscapes[Unpublished doctoral dissertation]. Cardiff University.

Sullins, D. S., Haukos, D. A., Craine, J. M., Lautenbach, J. M., Robinson, S. G., Lautenbach, J. D., ... Fierer, N. (2018). Identifying the diet of a declining prairie grouse using DNA metabarcoding. The Auk, 135 (3), 583-608. https://doi.org/10.1642/AUK-17-199.1

Sunde, P., Bølstad, M. S., \& Møller, J. D. (2003). Reversed sexual dimorphism in tawny owls, Strix aluco , correlates with duty division in breeding effort. Oikos , 101 (2), 265-278. https://doi.org/10.1034/j.16000706.2003.12203.x

Svensson, L. (1992). Identification guide to European passerines(4th ed.). Sturegatan, Stockholm, Sweden: British Trust for Ornithology.

Symondson, W. O. C. (2002). Molecular identification of prey in predator diets. Molecular Ecology , 11 (4), 627-641. https://doi.org/10.1046/j.1365-294X.2002.01471.x

Taberlet, P., Bonin, A., Zinger, L., \& Coissac, E. (2018).Environmental DNA: For Biodiversity Research and Monitoring . Oxford University Press.

Tercel, M. P. T. G., Symondson, W. O. C., \& Cuff, J. P. (2021). The problem of omnivory: A synthesis on omnivory and DNA metabarcoding.Molecular Ecology , 30 (10). https://doi.org/https://doi.org/10.1111/mec.15903

Thompson, K. A., \& Newmaster, S. G. (2014). Molecular taxonomic tools provide more accurate estimates of species richness at less cost than traditional morphology-based taxonomic practices in a vegetation survey.Biodiversity and Conservation , 23 (6), 1411-1424. https://doi.org/10.1007/s10531-014-0672-z

Tomiałojć, L. (2012). Reproduction and Population Dynamics of HawfinchesCoccothraustes coccothraustes in the Primeval Forest of Białowieża National Park (NE Poland). Acta Ornithologica ,47 (1), 63-78. https://doi.org/10.3161/000164512X653935

Valentini, A., Miquel, C., Nawaz, M. A., Bellemain, E., Coissac, E., Pompanon, F., .. Taberlet, P. (2009). New perspectives in diet analysis based on DNA barcoding and parallel pyrosequencing: The trnL approach. Molecular Ecology Resources , 9 (1), 51-60. https://doi.org/10.1111/j.1755-0998.2008.02352.x

von Haartman, L. (1978). An account of a small population of Hawfinches.Ornis Fennica , 55 , 132-133.

Wang, Y., Naumann, U., Eddelbuettel, D., John, W., \& Warton, D. (2012). mvabund - an R package for model-based analysis of multivariate abundance data. Methods in Ecology and Evolution , 3 (3), 471-474. https://doi.org/10.1111/j.2041-210X.2012.00190.x

Wesołowski, T., \& Neubauer, G. (2017). Diet of Marsh Tit Poecile palustris Nestlings in a Primeval Forest in Relation to Food Supply and Age of Young. Acta Ornithologica , 52 (1), 105-118. 
https://doi.org/10.3161/00016454AO2017.52.1.010

Westfall, P., \& Young, S. (1993). Resampling-Based Multiple Testing. New York: John Wiley \& Sons.

Wickham, H. (2016). Ggplot2: Elegant Graphics for Data Analysis . New York: Springer-Verlagg. Retrieved from https://ggplot2.tidyverse.org.

Yu, D. W., Ji, Y., Emerson, B. C., Wang, X., Ye, C., Yang, C., \& Ding, Z. (2012). Biodiversity soup: metabarcoding of arthropods for rapid biodiversity assessment and biomonitoring. Methods in Ecology and Evolution , 3 (4), 613-623. https://doi.org/10.1111/j.2041-210X.2012.00198.x

Zalewski, A., Szymura, M., Kowalczyk, R., \& Brzeziński, M. (2021). Low individual diet variation and high trophic niche overlap between the native polecat and invasive American mink. Journal of Zoology ,314 (2), 151-161. https://doi.org/https://doi.org/10.1111/jzo.12871

Zinger, L., Bonin, A., Alsos, I. G., Bálint, M., Bik, H., Boyer, F., ... Taberlet, P. (2019). DNA metabarcoding-Need for robust experimental designs to draw sound ecological conclusions. Molecular Ecology , 28 (8), 1857-1862. https://doi.org/10.1111/mec.15060

\section{Data Accessibility}

The ITS2 and COI MOTU presence/absence data supporting the work presented in this study will be openly available on Dryad following successful acceptance of this manuscript.

\section{Benefit sharing statement}

A research collaboration was developed with scientists from the organisation providing and collecting the faecal samples, with all collaborators listed as co-authors. The results of this research has been shared with the provider organisation and wider scientific community, with the research addressing a priority concern, in the case of the organism being studied. On broader terms, the commitment to multi-organisational partnerships is a commitment of the co-authors.

\section{Author contributions}

EHS led the study, field work and preparation of the manuscript. WOCS, IPV, PB and PO-tW conceptualised and managed the study. EHS processed and analysed the high-throughput sequencing data. Statistical analysis was conducted by EHS. EHS wrote the original draft, and all authors contributed to the writing and editing of the manuscript.

\section{Figures}

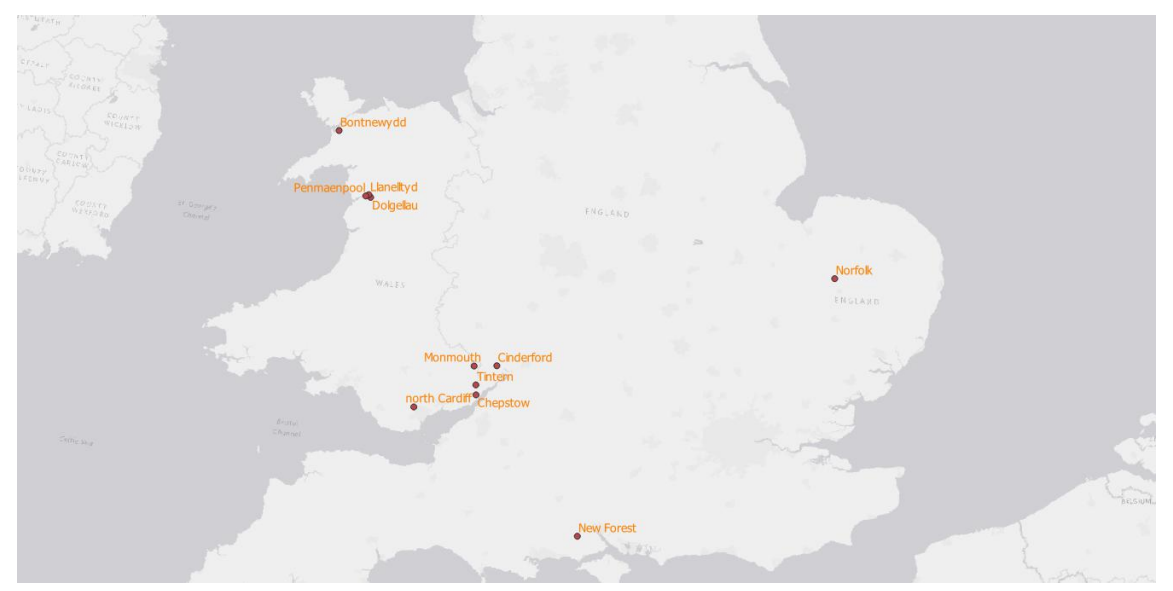


Figure 1 Locations of study sites where faecal samples were collected are shown as red dots. Map was produced on ArcGis v3.16.8 (QGIS Development Team, 2021).

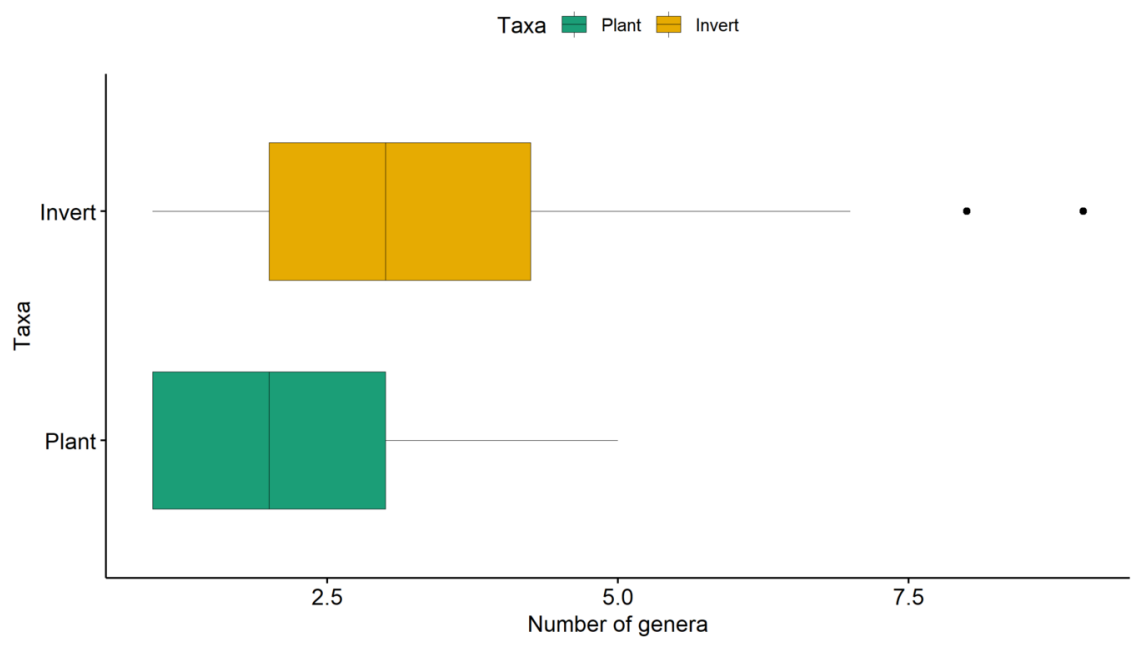

Figure 2 Box and whisker plot showing the difference in taxonomic richness of plant and invertebrate genera in the diet of Hawfinch.

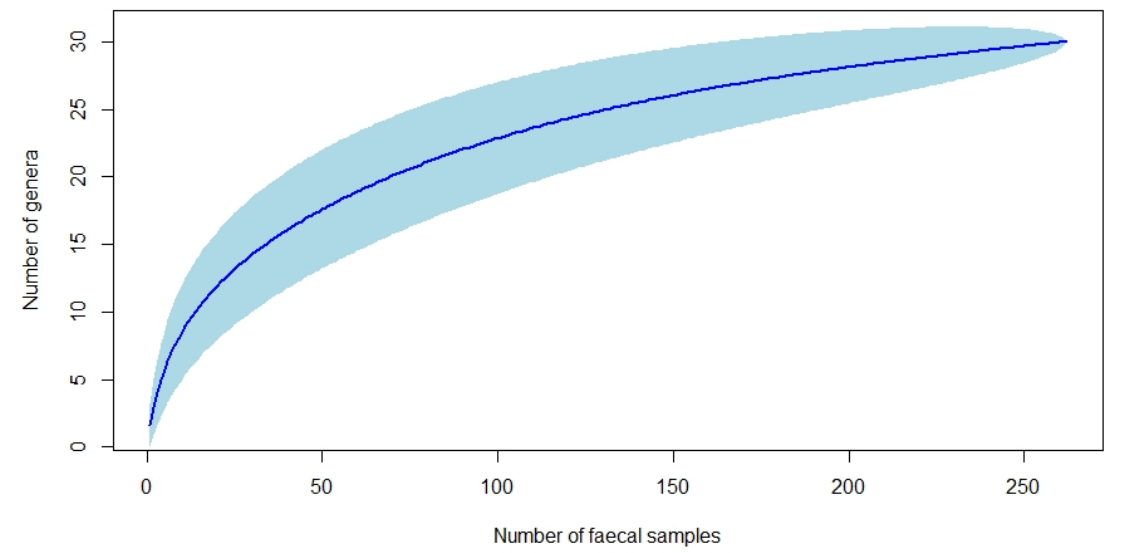

Figure 3 Species accumulation curves for UK sites based on accumulation of plant genera detected across successive faecal samples. Confidence intervals are overlaid in blue shading. 


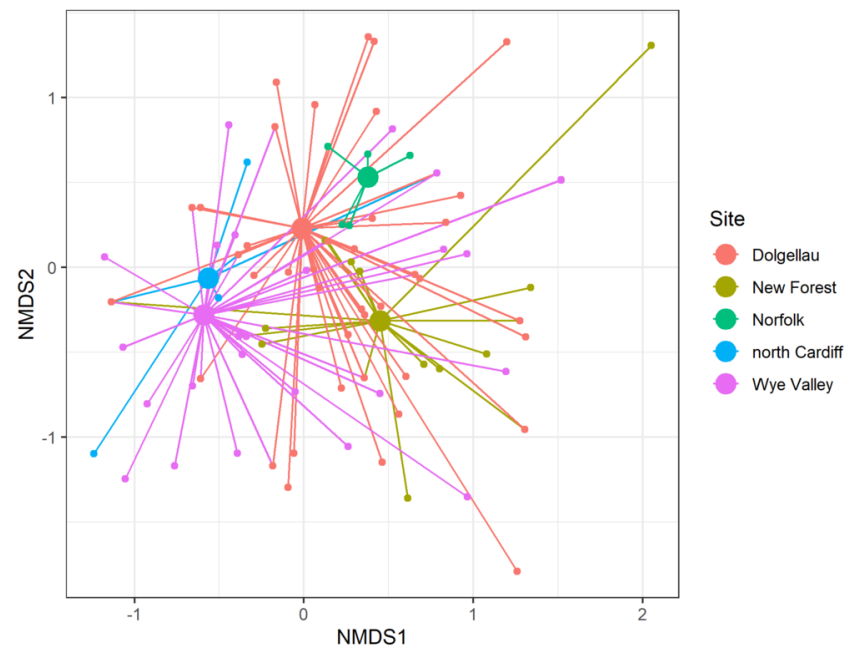

Figure 4 Spider plot for herbivorous taxa consumed by Hawfinch in different geographic regions. Smaller nodes represent individual Hawfinch with connecting lines joining the individual to the mean centroid (larger nodes) of its region. Stress $=0.06$.

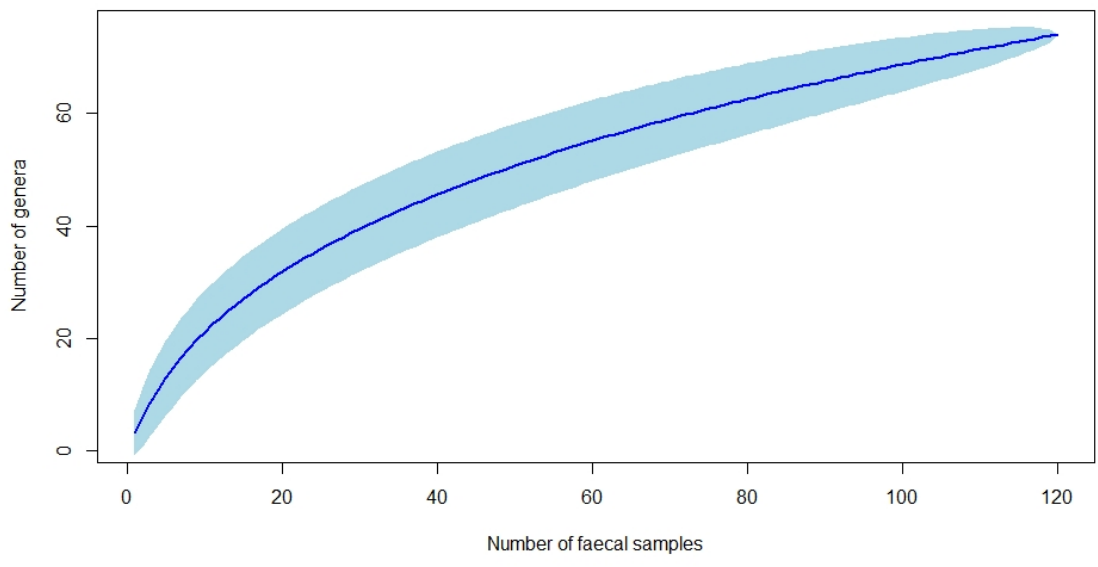

Figure 5 Species accumulation curves for UK sites based on accumulation of invertebrate genera detected across successive faecal samples. Confidence intervals are overlaid in blue shading. 


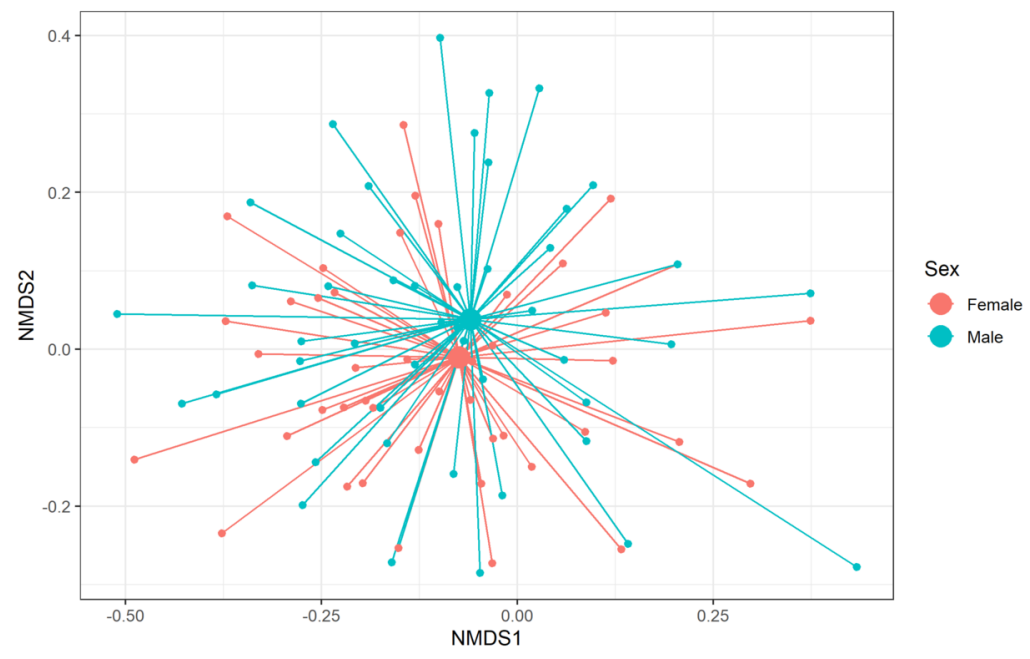

Figure 6 Spider plot for invertebrate taxa consumed by male and female Hawfinch. Smaller nodes represent individual Hawfinch with connecting lines joining the individual to the mean centroid (larger nodes) of its sex. Stress $=0.07$. 